\title{
Türkiye'de Devlet İç Borçlanma Senetleri Reel Faizinin Süreğenliği: Parametrik Olmayan Bir Uygulama
}

Özer ARABACI*

\section{ÖZET}

Süreğenlik, bir şok karşısında ele alınan zaman serisinin önceki dönem seviyesine ya da ortalamasına geri dönme hızıdır. Bu nedenle, süreğenliğin önemine ilişkin tartışmalar makroekonomik politikaların değerlendirilmesinde merkezi bir role sahiptir. Bu çalışma, hem exante reel hem de expost reel olmak üzere, Devlet Iç Borçlanma Senetleri faizi süreğenliğini Marques (2004) ve Dias ve Marques (2010) tarafindan geliştirilen parametrik olmayan yaklaşımla ve hareketli ortalama ile kayan pencereler yöntemine dayanan ortalamalar kullanarak incelemektedir. Elde edilen bulgulara göre, Türkiye ekonomisi için hem exante hem de expost reel faiz oranlarl yüksek bir süreğenliğe sahiptir. 2011 yılı başı itibariyle her iki reel faiz oranının da süreğenliği azalmaktadır. Bu durum, tüketim temelli varlık fiyatlandırma modeli çerçevesinde ele alındığında, Türkiye ekonomisi için kredi büyümesinin büyük boyutlara ulaştığı ve tasarruf oranlarının gerçekten de rahatsı edecek derecede düşük seyrettiği bu dönem için oldukça tutarlı bir sonuçtur.

Anahtar Kelimeler: Süreğenlik, Reel Faiz, Ortalamaya Dönme Eğilimi.

JEL Sinıflandırması: E43, E44.

The Persistence of Real Interest of Government Domestic Debt Securities in Turkey: A Nonparametric Application

\section{ABSTRACT}

Persistence is the turnover speed of the time series undertaken in case of a shock to a previous term level or its average. Therefore, discussions related to the significance of persistence have a central role in macroeconomic policies assessment. By using a nonparametric approach developed by Marques (2004) and Dias and Marques (2010), this study is analyzed the persistence of both ex ante and ex post real interests of Government Domestic Debt Securities via means which are based on moving average and sliding window approach. Findings show that, both ex ante and ex post real interest rates have a high persistence for Turkish economy. Either real interest rate persistence is on serious decrease as of the beginning of 2011. This situation, when dealt with consumption based asset pricing model frame, is a notably consistent results for this term during which the credit growth has reached large sizes and the savings ratio has been inconveniently low.

Keywords: Persistence, Real Interest Rate, Mean Reversion.

Jel Classification: E43, E44.

\footnotetext{
* Yrd. Doç. Dr. Özer Arabacı,, Uludağ Üniversitesi, İktisadi ve İdari Bilimler Fakültesi, ozerarabaci@uludag.edu.tr
} 


\section{GíRiş}

Bir zaman serisi için süreğenliğin basit bir tanımı bir şok karşısında serinin önceki dönem seviyesine geri dönme hızı olarak verilebilir. Süreğenliğin yüksek olduğu bir seride şoka verilen tepki hızlı ve önceki dönem değerine ya da ortalamaya yakınsama yavaş olacaktır. İlgili değişkenin şoka verdiği tepkinin ölçülebilmesi, yalnızca ekonomi politikalarının etkinliğinin değerlendirilmesi açısından değil ayrıca şok karşısında uygulanacak politikaların zamanlaması ve şokun istenmeyen etkilerinin ortaya çıkış sürecinde azaltılması anlamında da oldukça önemlidir (Caleiro, 2012, 206). Bu nedenle, süreğenlik ve süreğenliğin önemine ilişkin tartışmalar makroekonomik politikaların değerlendirilmesinde merkezi bir role sahiptir. Öte yandan, ilgili literatür ancak 80'li yılların başlarına kadar uzanabilmektedir. Teorik ve ampirik düzeyde makroekonomik açıklamalar süreğenlik kavramını sıklıkla vurgulamaktadır. Örneğin, Mishkin (2007) enflasyon hedeflemesi rejiminde, yüksek bir enflasyon süreğenliğinin para politikasının maliyetini arttırdığını belirtmektedir. Svenson (1997) enflasyon sözleşmelerinin varlığının işsizlik ve toplam çıktı serilerinde süreğenliğine neden olduğunu vurgulamaktadır. Hane halklarının cari dönem tüketiminin, geçmiş dönem tüketimlerine alışkanlıklar üzerinden bağlı olduğu savı Dusenberry (1949)'a dayanmaktadır. Rotenberg ve Woodford (1997) aşamalı fiyat ve ücret ayarlamalarının parasal şokların reel etkilerinin ortaya çıkmasına ve bu etkilerin kalıcı olmasına yol açtığını belirtmektedir.

$\mathrm{Bu}$ çalışmanın amacı, parasal aktarım mekanizması modelleri, neo klasik büyüme modeli, tüketim temelli varlık fiyatlandırma modeli gibi teorik modellerde anahtar bir rol üstlenen reel faiz değişkeninin süreğenliğini ve ortalamaya dönme eğilimini Türkiye ekonomisi için değerlendirmektir. Açıktır ki ortalamaya dönme eğilimi ya da süreğenlik ölçüsünün bilinmesi politika uygulamalarının etkinliği ve bu uygulamaların piyasaların işlevselliğine uygunluğu anlamında önem arz etmektedir.

Teorik olarak, Tüketime Dayalı Varlık Fiyatlama Modeli (Lucas, 1978), bir ekonomi için reel faiz ve kişi başına reel tüketim büyümesi serilerinin aynı bütünleşme derecesine sahip olması gerektiğini ifade eder. Rose (1988) ele aldığ farklı ekonomilere ait reel faiz serilerinin birim kök içerdiğini buna karşılık, bu ekonomiler için kişi başına reel tüketim büyümesi serilerinin durağan olduğunu belirtmektedir. Das vd. (2012), Rose (1988)'de ortaya koyulan bu uyuşmazlığın aslında Neo Klasik Büyüme modelinin değerlendirilmesiyle anlaşılabilir bir hal aldığını açıklamaktadır. Cass (1965) ve Koopsmans (1965)'e göre durgun durum (steady state) reel faiz oranı, zaman tercihi, riskten kaçınma ve teknolojik gelişimin büyüme oranının bir fonksiyonudur. Öte yandan, kişi başına reel tüketim büyümesi ise sadece teknolojik gelişimin büyüme oranının bir fonksiyonudur. Bu durumda, teknolojik gelişimin büyüme oranını dışındaki faktörlerden kaynaklanan bir değişim sadece reel faiz oranında bir değişim yaratırken, kişi başına reel tüketim büyümesi üzerinde bir etkide bulunamayacaktır (Neely ve Rapach, 2008, 612). Böylece, reel faiz oranının bütünleşme derecesi ve süreğenliği bu durumdan etkilenirken, kişi başına reel tüketim büyümesi ise etkilenmeyecektir. Benzer 
şekilde, Baxter ve King (1993), hükümet harcamalarındaki artış şeklindeki bir mali şokun, geçici de olsa, reel faizin artması yönünde ve tüketim büyümesi üzerinde olduğundan daha büyük bir oranda süreğenlik yaratacağına işaret etmektedir. Ek olarak, parasal şokların da fiyat yapışkanlıkları, fiyat ayarlamaları vb. nedenlerle reel faiz üzerinde kalıcı etkiler yaratabileceği ve kişi başına reel tüketim büyümesi ile arasında bütünleşme derecesi farklılığı ortaya çıkarabileceği literatürde vurgulanmaktadır (Neely ve Rapach, 2008, 613).

Öte yandan, literatürün bir başka kolu da reel faiz serisinde sadece süreğenliğinin değil, ortalamaya dönme eğiliminin de yüksek olduğuna işaret ederek, veri yaratma sürecinin kesirli bütünleşik bir yapıda olduğunu ya da diğer bir ifade ile, bütünleşme derecesinin I(0) veya I(1) gibi ikili bir yapı yerine, $\mathrm{I}(\mathrm{d})$ ve $0<\mathrm{d}<1$ şeklinde olabileceğini iddia etmektedir (Örneğin bknz. Lai ,1997; Tsay, 2000). Benzer şekilde, Türkiye ekonomisi için, Turgutlu (2004), Kutlu ve Turgut (2006) ve Yurttagüler ve Kutlu (2013), reel faizin uzun hafiza özelliği taşıdığını ve oldukça dirençli bir sürece sahip olduğunu raporlamışlardır. Aslında bir adım daha ileri gidilerek, kesirli bütünleşik yapının da zamana bağlı değişen bir tutum izlediğini ya da yapısal değişim içerebileceğini varsaymak, makroekonomik teori açısından çok daha gerçekçi olacaktır. Bu anlamda literatürde bir dizi çalışma bulunmasına rağmen (Örneğin bknz. Diebold ve Inoue, 2001; Gil Alana, 2004; Gil-Alana ve Moreno, 2012), genel kabul görmüş bir yaklaşım bulunmamaktadır.

Diğer taraftan, Marques (2004) ve Dias ve Marques (2010) süreğenlik ölçüsü olarak ortalamaya dönme eğiliminin kullanıldığı parametrik olmayan bir istatistik ve ayrıca ele alınan örneklemde süreğenlikteki bir değişimin testi için de izlenebilecek bir yol önermektedirler. Ek olarak bu yöntem, ele alınan zaman serisinin ortalaması zamana bağlı değişen bir şekilde ele alındığında, serinin sahip olduğu süreğenlik derecesinin zaman içerisinde değişiminin göz önüne alınabilmesine de imkân tanır. Bu çalışma, exante ve expost reel DİBS 90 faizinin süreğenliklerini Marques (2004) ve Dias ve Marques (2010) tarafından geliştirilen yöntemle ve hareketli ortalama ile kayan pencereler yöntemine dayanan ortalama yaklaşımlarıyla incelemektedir. Elde edilen bulgulara göre, Türkiye ekonomisi için hem exante hem de expost reel faiz oranları yüksek bir süreğenliğe sahiptir. Ayrıca, exante reel faiz oranlarının süreğenliğinin zaman içinde gösterdiği değişkenlik, expost reel faiz oranlarının süreğenliğine göre daha yüksektir.

Çalışmanın geri kalanı şu şekilde organize edilmiştir. İkinci bölümde çalışmada kullanılan metodoloji tanıtılmış, üçüncü bölümde uygulama sonuçlarına yer verilmiş ve son bölüm genel bir değerlendirme için ayrılmıştır.

\section{METODOLOJi}

Genel olarak, bir zaman serisi değişkeninin süreğenlik ölçüsü, o seriye ilişkin otoregresif modeldeki otoregresif katsayıların toplamı olarak ele alınmaktadır. $\mathrm{Bu}$ tanım aslında Andrews ve Chen (1994)'in çalışmasına dayanmakta ve ortalamaya dönme eğilimi 
kavramıyla yakın bir ilişki göstermektedir. Şöyle ki, $y_{t}$ zaman serisi için tek değişkenli bir $\mathrm{AR}(\mathrm{p})$ modeli

$$
y_{t}=\alpha+\sum_{i=1}^{p} \beta_{i} y_{t-i}+\varepsilon_{t}
$$

şeklinde olsun. Bu durumda denklem (1), fark modeli olarak denklem (2) şekilde aşağıdaki gibi ele alınırsa,

$$
\Delta y_{t}=\sum_{i=1}^{p-1} \delta_{i} \Delta y_{t-i}+(\rho-1)\left(y_{t-1}-\mu\right)+\varepsilon_{t}
$$

burada, $\delta_{i}=-\sum_{i=1}^{p} \beta_{i}$ ve $\rho=\sum_{i=1}^{p} \beta_{i}$ olup, $y_{t}$ zaman serisinin koşullu olmayan ortalaması $\mu=\left(\frac{\alpha}{1-\rho}\right)$ şeklinde olacaktır. Açıktır ki, otoregresif katsayıların toplamı olarak ele alınan $\rho$ parametresinin denklem (2)'de yer aldığ terim, $(\rho-1)\left(y_{t-1}-\mu\right), y_{t}$ serisinin ortalamaya dönme eğilimini ortaya koymaktadır. $y_{t}$ serisinde, $|\rho|<1$ ya da $(\rho-1)<0$ kısıtı altında, $\mathrm{t}-1$ periyotunda ortalamadan bir birimlik sapma, t periyotunda $(\rho-1)$ kadarlık değişime neden olacaktır. $\mathrm{Bu}$ nedenle, süreğenlik derecesi $(\rho)$ ve ortalamaya dönme eğilimi $(\rho-1)$ birbirleriyle ters ilişski içerisinde olan iki kavramdır. Yüksek dereceli bir süreğenlik, zayıf bir ortalamaya dönme eğilimini ifade eder (Belbute ve Caleiro, 2013, 449).

İlk olarak Marques (2004) ve daha sonra da Dias ve Marques (2010) bu sade fakat güçlü ilişkiden hareketle, süreğenlik ölçüsü olarak ortalamaya dönme eğiliminin kullanıldığ basit bir istatistik önermektedirler. Buna göre, ele alınan seri süreğenliğin düşük olduğu bir zaman serisi ise zaman yolu grafiği boyunca kendi ortalamasını sıkça kesecektir. Farklı olarak, bir zaman serisinde süreğenlik yüksek derecede ise, bu zaman serisi ortalamaya dönme eğiliminin düşük seviyede olduğu, ya da başka bir ifade ile zaman yolu grafiği incelendiğinde serinin kendi ortalamasını kesme frekansının görece daha az olduğu bir zaman serisidir. Buna göre, Marques (2004) ve Dias ve Marques (2010) süreğenlik ölçütü olarak $\hat{\gamma}$ istatistiğini, ele alınan zaman serisinin kendi ortalamasını kesmesinin seyrekliği olarak,

$$
\hat{\gamma}=1-\frac{n}{T}
$$

şeklinde formüle etmektedir. Burada, $n, T+1$ gözlemden oluşan bir zaman aralığında ele alınan zaman serisinin kendi ortalamasını kesme sayısıdır ve $0 \leq \hat{\gamma} \leq 1$ olacaktır. Ayrıca, 0.5 değerine yakın $\hat{\gamma}$ istatistiği değeri süreğenliğin olmadığını, 1'e yakın $\hat{\gamma}$ istatistiği değeri 
süreğenliğin yüksek olduğunu ve 0.5 'in altındaki $\hat{\gamma}$ değeri ise negatif otokorelasyonu işaret eder (Marques, 2004, 19).

$\mathrm{Bu}$ ölçüt, başlıca iki nedenden dolayı yukarıda bahsedilen parametrik yaklaşıma göre daha kullanışlıdır. Bunlardan birincisi, yukarıdaki parametrik yaklaşımla süreğenlik ölçütü hesaplayabilmek için veri yaratma sürecinin durağan bir stokastik süreç olması gerekir. İkinci önemli neden ise, parametrik bir yaklaşımla süreğenlik ölçütü hesabında, ilgili modelde herhangi bir spesifikasyon hatası olmadan $\hat{\rho}$ istatistiğinin elde edilmesi gerekmektedir. Bunlara ek olarak, Dias ve Marques (2010) $\hat{\gamma}$ ve $\hat{\rho}$ istatistiklerinin sonlu örneklem özelliklerini araştırdıkları Monte-Carlo simülasyonuna dayanan çalışmalarında, $\hat{\gamma}$ istatistiğinin $\hat{\rho}$ istatistiğine göre yansızlık ve aykırı gözlemlere ilişkin robust olma konusunda daha üstün olduğunu raporlamıştır.

Ayrıca, tahmin edilen $\hat{\gamma}$ istatistiğinin anlamlılı̆̆ını test etmek için, Kiefer and Vogelsang (2002) tarafından önerilen ve bir modelin kalıntılarının serisel korelasyonlu olduğu durumda, alternatif bir $t$ istatistiği olarak kullanılabilecek, standart normal dağılıma sahip aşağıdaki t oranı kullanılabilir (Dias ve Marques, 2010, 264).

$$
t=\frac{\sqrt{T}(\hat{\gamma}-\gamma)}{\sqrt{s_{\hat{\gamma}}^{2}(T)}}
$$

Burada, $T$ örneklem hacmi, $\hat{\gamma}$ denklem (3) üzerinden elde edilen süreğenlik ölçütü ve $\gamma$ ise süreğenliğin olmadığı durumdaki istatistik değeri olan 0.5 değeri olarak ele alınır. $s_{\hat{\gamma}}^{2}(T)$ ise $\sqrt{T}(\hat{\gamma}-\gamma)$ ifadesinin asimptotik varyansı olan $\sigma_{\hat{\gamma}}^{2}(T)$ 'nin bir tahminidir. Bu tahmin literatürde Bartlett, Parzen ya da Kuadratik Spectral Kernel metotlarından biri kullanılarak ve bant genişliği olarak da örneklem hacmi $(T)$ ele alınıp tahmin edilmektedir.

Son olarak, ele alınan zaman serisi boyunca, herhangi bir spesifik tarihte süreğenlikte bir değişimin olup olmadığı da test edilebilir. Bu amaçla, iki kukla değişkene ihtiyaç vardır. Bunlardan birincisi $x_{t}, \mathrm{~T}+1$ gözlemden oluşmuş bir $y_{t}$ serisi için, zaman yolu boyunca ortalamasını kestiği periyotlarda 1 , kesmediği periyotlarda ise 0 değerini alan, ikincisi olan $d_{t}$ ise ilgili spesifik tarihe kadar 0 ve o tarihten sonra ise 1 değerini alan kukla değişkenlerdir. Bu durumda $x_{t}$ 'nin bir kesme terimi ve $d_{t}$ üzerine regres edilmesi ile aşağıdaki denklem (5)'e ulaşılır.

$$
x_{t}=\alpha_{1}+\alpha_{2} d_{t}+u_{t}
$$

Burada, $\alpha_{1}$ parametresi ilgili spesifik tarihe kadar olan periyot için geçerli süreğenlik ölçütü $\gamma_{1}$ için $\alpha_{1}=1-\gamma_{1}$ ilişkisini verirken, $\alpha_{2}$ parametresi ise, spesifik tarihe kadarki periyot için süreğenlik ölçütü olan $\gamma_{1}$ ve spesifik tarihten sonraki süreğenlik ölçütü olan $\gamma_{2}$ arasındaki 
$\alpha_{2}=\gamma_{1}-\gamma_{2}$ ilişkisini verir. $\mathrm{Bu}$ durumda, denklem (5)'deki regresyonun tahmini ile elde edilecek olan $\hat{\alpha}_{2}$ istatistiğinin istatistiksel olarak sıfırdan farklı olması $\hat{\gamma}_{1}$ ve $\hat{\gamma}_{2}$ istatistiklerinin istatistiksel olarak birbirlerinden farklı olması anlamına gelecektir (Dias ve Marques, 2010, 265).

\section{UYGULAMA}

Reel faiz oranı, ex-post ve ex-ante reel faiz olmak üzere iki farklı şekilde elde edilebilir. Ex-post reel faiz oranı nominal faiz oranının gerçekleşen enflasyon oranından arındırılmasıyla elde edilirken, ex-ante reel faiz oranı ise nominal faiz oranının beklenen enflasyon oranından arındırılmasıyla elde edilir ${ }^{1}$. Bu çalışmada, doksan gün vadeli devlet iç borçlanma senetleri (DİBS 90) için, aylık olarak (2001:06 - 2013:10), hem exante hem de expost reel faiz oranı kullanılmıştır ${ }^{2}$. Gerçekleşen ve beklenen enflasyon verileri merkez bankası veri dağıtım sisteminden elde edilmiştir. Aşağıda grafik 1, DİBS 90 için nominal, exante ve expost reel faiz oranlarının zaman yolu grafiğini göstermektedir.

Grafik 1: DiBS90 Nominal, Exante ve Expost Reel Faiz Oranlart

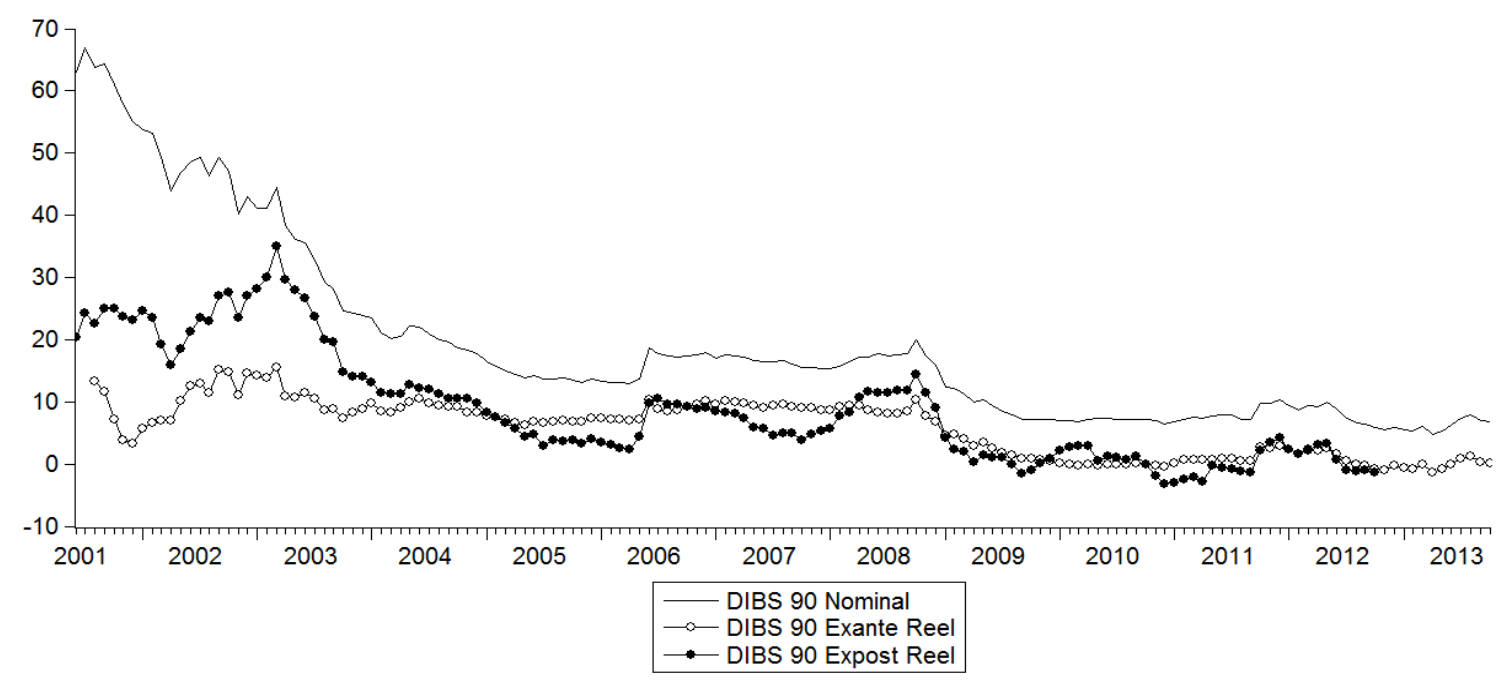

Metodoloji bölümünde tanıtılan Marques (2004) ve Dias ve Marques (2010) tarafından önerilen süreğenlik ölçütü, $\hat{\gamma}$, istatistiğinin reel faiz oranları için hesaplanabilmesi, Exante ve Expost reel faiz oranlarının ortalamalarının elde edilmesiyle mümkündür. Bu çalışmada, reel faiz oranının ortalamasının ele alınan örneklem boyunca sabit kalmadı̆̆ı, zaman içinde değiştiği varsayımından hareketle ve Marques (2004)'deki şekliyle ve de ayrıca aylık veriler ile çalışıldığından ötürü, reel exante ve reel expost faiz serileri için 13' erli hareketli ortalama

\footnotetext{
${ }^{1}$ Reel faiz oranları hesaplanırken, $r=\left(\frac{1+i}{1+\pi}-1\right) x 100$ formülü dikkate alınmıştır.

${ }^{2}$ DIBS fiyat endekslerinden hareketle faiz oranlarının hesaplanması için bknz. IMKB DIBS Endeksleri s. 22-24. http://www.borsaistanbul.com/data/kilavuzlar/IMKB\%20Endeksleri.pdf
} 
alınarak zaman içerisinde değişen ortalamaları elde edilmiştir. Aşağıda grafik 2 ve grafik 3 , sırasiyla exante ve expost reel faiz serilerini, hareketli ortalamalarını ve bu ortalamadan sapmaları göstermektedir.

Açıktır ki, her iki reel faiz oranı için ortalamadan sapmalar şeklinde elde edilen yeni serilerin sıfır (0) değeri etrafındaki hareketleri, reel faiz serilerinin kendi hareketli ortalamaları etrafındaki hareketleriyle, ortalamaya dönme eğilimi açısından, aynı bilgiyi taşımaktadır. $\mathrm{Bu}$ açıdan, ortalamadan sapma serileri üzerinden grafik 2 ve grafik 3 birlikte değerlendirildiğinde rahatça görülebileceği gibi, exante reel faizin expost reel faize göre daha yüksek bir ortalamaya dönenme eğilimine ya da diğer bir ifade ile expost reel faiz, exante reel faize göre daha yüksek bir süreğenliğe sahiptir.

\section{Grafik 2: Exante Reel Faiz, Hareketli Ortalamast ve Ortalamadan Sapmalar}

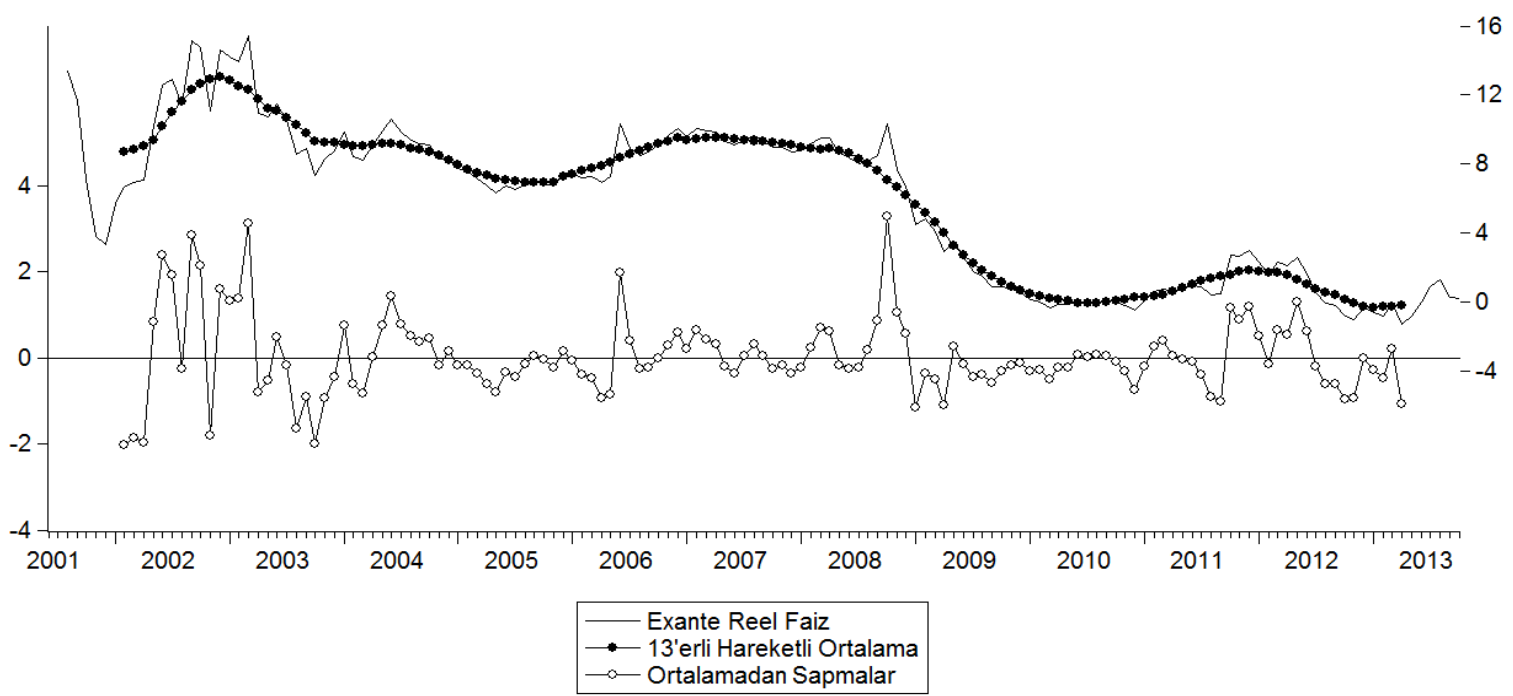

Grafik 3: Expost Reel Faiz, Hareketli Ortalaması ve Ortalamadan Sapmalar

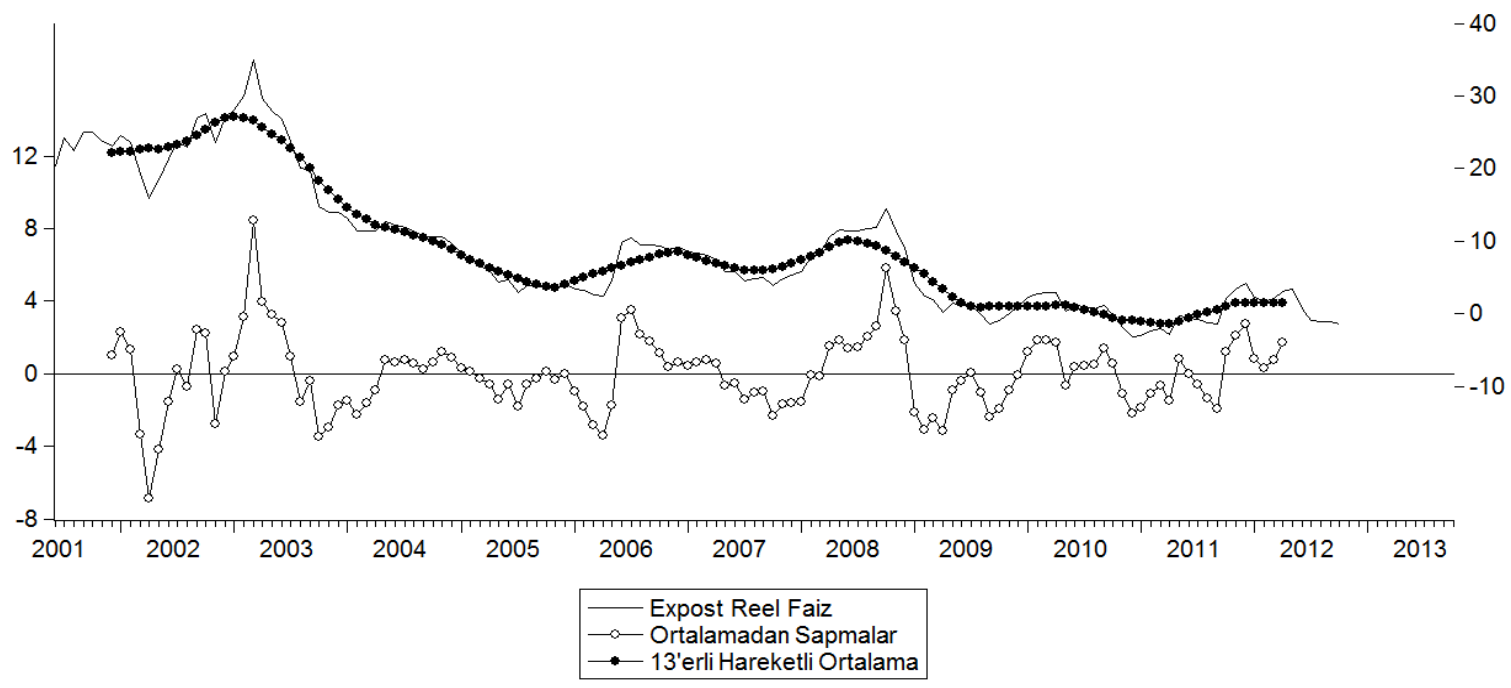


Gerçekten de, Tablo 1'den de görülebileceği gibi, exante reel faiz serisi için, denklem 3 kullanılarak elde edilen $\hat{\gamma}$ istatistiği 0.70 iken expost reel faiz serisi için $\hat{\gamma}$ istatistiği değeri 0.79'a eşittir. Öte yandan, Kuadratik Spectral Kernel kullanılarak hesaplanan $s_{\hat{\gamma}}(T)$ istatistiği değeri, exante reel faiz için 1.86, expost reel faiz serisi için ise 1.09 olarak bulunmuştur. $\mathrm{Bu}$ durumda, denklem 4'den elde edilen $t$ istatistiği değerleri sırasıyla, exante reel faiz için 1.25 ve expost reel faiz için 2.97 olup, exante reel faiz süreğenliğine ilişkin hesaplanan $\hat{\gamma}$ istatistiğinin $\% 10$ ve expost reel faiz için ise yaklaşık olarak $\% 1$ anlamlılık düzeyinde istatistiksel olarak anlamlı olduğunu göstermektedir.

Tablo 1: Exante ve Expost Reel Faiz Süreğenliği

\begin{tabular}{llll}
\hline \hline DíBS90 Exante & $\hat{\gamma}=0.70$ & $s_{\hat{\gamma}}(T)=1.86$ & $t=1.25$ \\
DiBS90 Expost & $\hat{\gamma}=0.79$ & $s_{\hat{\gamma}}(T)=1.09$ & $t=2.97$ \\
\hline \hline
\end{tabular}

İkinci olarak, metodoloji başlığı altında belirtildiği şekilde ele alınan örneklem boyunca, herhangi bir spesifik tarihte exante reel ve expost reel faizlerin süreğenliklerinde bir değişimin olup olmadığı da test edilmiştir. Bu amaçla, 2002 sonrası Türkiye ekonomisi için reel faiz süreğenliğinde bir değişim yaratabilecek spesifik tarihler olarak: 2005 yılı ortaları ve sonrası itibariyle mali baskınlığın azalmış olması, 2006 yılı başı itibariyle açık enflasyon hedeflemesine geçilmesi, 2006 Mayıs - Haziran aylarında uluslararası finansal piyasalarda yaşanan dalgalanmalar ve TCMB'nin buna verdiği sert tepki, 2008 Eylül ayında Lehman Brothers'ın iflası ve son olarak 2010 yılı Aralık ayı itibariyle açık enflasyon hedeflemesine finansal istikrar amacının entegre edildiği tarihler ele alınmıştır.

Tablo 2: Reel Faiz Süreğenliğinde Değişim

\begin{tabular}{|c|c|c|c|c|c|c|c|c|c|c|c|c|}
\hline & \multicolumn{3}{|c|}{2006 OCAK } & \multicolumn{3}{|c|}{2006 HAZIRAN } & \multicolumn{3}{|c|}{$2008 E Y L \ddot{U} L$} & \multicolumn{3}{|c|}{2010 ARALIK } \\
\hline & $\hat{\gamma}_{1}$ & $\hat{\gamma}_{2}$ & $\hat{\alpha}_{2}$ & $\hat{\gamma}_{1}$ & $\hat{\gamma}_{2}$ & $\hat{\alpha}_{2}$ & $\hat{\gamma}_{1}$ & $\hat{\gamma}_{2}$ & $\hat{\alpha}_{2}$ & $\hat{\gamma}_{1}$ & $\hat{\gamma}_{2}$ & $\hat{\alpha}_{2}$ \\
\hline $\begin{array}{l}\text { DïBS90 } \\
\text { Exante }\end{array}$ & 0.72 & 0.65 & $\begin{array}{l}0.11 \\
(0.06)\end{array}$ & 0.67 & 0.72 & $\begin{array}{l}0.06 \\
(0.13)\end{array}$ & 0.67 & 0.72 & $\begin{array}{c}0.07 \\
(0.12)\end{array}$ & 0.69 & 0.70 & $\begin{array}{c}0.00 \\
(0.96)\end{array}$ \\
\hline $\begin{array}{l}\text { DIBSS90 } \\
\text { Expost }\end{array}$ & 0.76 & 0.80 & $\begin{array}{c}0.04 \\
(0.54)\end{array}$ & 0.75 & 0.80 & $\begin{array}{r}0.06 \\
(037)\end{array}$ & 0.78 & 0.76 & $\begin{array}{c}-0.04 \\
(0.51)\end{array}$ & 0.77 & 0.80 & $\begin{array}{l}0.02 \\
(0.89)\end{array}$ \\
\hline
\end{tabular}

Tablo 2'de $\hat{\gamma}_{1}$ ve $\hat{\gamma}_{2}$, üst satırda belirtilen tarihin öncesi ve sonrası dönemler için elde edilen süreğenlik ölçütlerini göstermektedir. $\hat{\alpha}_{2}$ ise $\hat{\gamma}_{1}$ ve $\hat{\gamma}_{2}$ arasındaki farkın istatistiksel olarak anlamlı olup olmadığının testi için (5) numaralı denklemde verilen regresyon eşitliğindeki $d_{t}$ nin tahmin edilen katsayısıdır. Daha önce metodoloji başlığı altında da belirtildiği gibi $\hat{\alpha}_{2}$ 'nin istatistiksel olarak anlamlılığı, $\hat{\gamma}_{1}$ ve $\hat{\gamma}_{2}$ arasındaki farkın istatistiksel 
olarak anlamlı olması yada diğer bir ifade ile $\hat{\gamma}_{1}-\hat{\gamma}_{2}$ değerinin istatistiksel olarak anlamlı şekilde sıfırdan farklı olması anlamına gelir.

Ele alınan dönemler bazında, exante reel faiz için süreğenlik ölçütü 0.65-0.72, expost reel faiz için ise 0.75-0.81 bandında değişmektedir. Expost reel faiz için ele alınan ve süreğenlikte bir değişime neden olabileceği varsayılan tarihlerin hiçbirinde süreğenlik ölçütündeki değişim anlamlı bulunmamıştır. Öte yandan exante reel faiz için, ele alınan tarihlerden sadece bir tanesinde 2006 Ocak öncesi ve sonrası dönem için ve ancak \%10 anlamlılık düzeyinde süreğenlikteki değişim istatistiksel olarak anlamlı, diğerlerinde ise istatistiksel olarak anlamsız bulunmuştur. 2006 Ocak öncesi dönem için $\hat{\gamma}_{1}, 0.65$ olarak elde edilmişken, 2006 Ocak sonrası dönem için hesaplanan süreğenlik ölçütü $\hat{\gamma}_{2}, 0.72$ olarak bulunmuş, (5) numaralı denklemde verilen regresyon eşitliğindeki $d_{t}$ 'nin tahmin edilen katsayısı olan $\hat{\alpha}_{2}, 0.11$ olarak tahmin edilmiş ve $p$ değeri 0.06 olarak elde edilmiştir.

Son olarak, 3'er y1llık olmak üzere kayan pencereler yöntemi kullanılarak exante ve expost reel faiz süreğenlikleri hesaplanmıştır. Hesaplamalarda her yeni bir ayın örnekleme eklendiği yeni pencerede bir önceki örneklem penceresinin ilk ayı örneklemden çıkarılmış ve buna göre elde edilen yeni reel faiz ortalamasına göre $\hat{\gamma}$ istatistiği hesaplanmıştır. Elde edilen sonuçlar aşağıda grafik 4'te sunulmuştur.

Grafik 4: Kayan Pencere Yöntemiyle Exante ve Expost Reel Faiz Süreğenlikleri

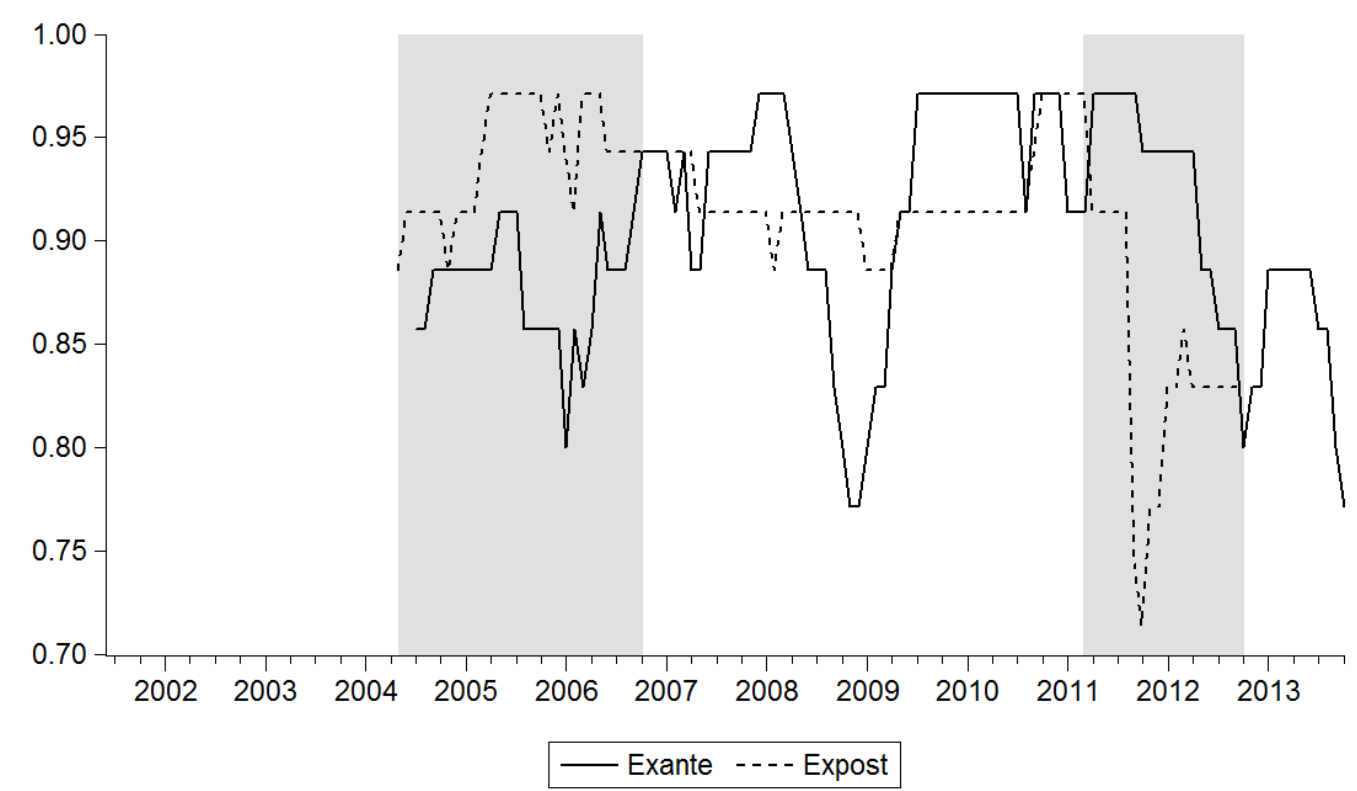

Grafik 4'te sunulan bulgulara göre, hem expost hemde exante reel faiz, birkaç özel dönem dışında, oldukça yükssek bir süreğenliğe sahiptir. 2006 yılı ortalarına kadar expost reel faiz süreğenliği exante reel faiz süreğenliğine göre daha yüksektir. Özellikle 2006 yılı 
itibariyle expost reel faizin süreğenliği, 2010 yılı sonları ve 2011 yılı başları hariç olmak üzere, azalma eğilimindedir. Yine özellikle expost reel faiz süreğenliği, 2011'in ilk çeyreğinden sonra ciddi bir azalma göstermiş 0.70 seviyelerine gerilemiş 2012 itibariyle de 0.80-0.85 bandına yerleşmiştir. Bu değerler 2011 öncesi dönemdeki kararlılık gösterdiği 0.900.97 bandının oldukça altındadır. Exante reel faiz süreğenliği ise 2006 yılı başlarından başlamak üzere 2008 yılına kadar bir artış eğilimindedir. Exante reel faiz için 2008 yılı sonu 2009 y1lı başında dip yapan süreğenlik, bu tarihten sonra 2009 yılı son çeyreğinden başlamak üzere 2011 yılı ilk çeyreğine kadar oldukça yüksek seyretmiştir. 2011 y1lı ilk çeyreğinden itibaren ise exante reel faiz süreğenliği expost reel faize benzer şekilde ancak biraz daha ağır biçimde bir azalış eğilimine girmiştir.

\section{SONUÇ}

Marques (2004) ve Dias ve Marques (2010)'in süreğenlik ölçütü olarak ele alınan zaman serisinin kendi ortalamasını kesmesinin seyrekliği olarak tanımladığ $\hat{\gamma}$ istatistiği, parametrik olmayan bir yöntemdir. Bu açıdan, hem veri yaratma sürecinin durağan bir stokastik süreç olmasını, hem de süreğenlik hesabı için tahmin edilmesi gereken modelin herhangi bir spesifikasyon hatası içerip içermediği hususunda herhangi bir endişeyi gerektirmez. Ayrıca, $\hat{\gamma}$ istatistiğini tahmin etmek için gereken ortalamanın zamana bağlı değişen bir yapıda ele alınması durumunda dinamik bir süreğenlik ölçütü bulunabilmesine de imkân tanır.

$\mathrm{Bu}$ çalışmada parasal aktarım mekanizması modelleri, neo klasik büyüme modeli, tüketim temelli varlık fiyatlandırma modeli gibi teorik modellerde anahtar bir rol üstlenen reel faiz değişkeninin süreğenliğini ve ortalamaya dönme eğilimini Türkiye ekonomisi için değerlendirilmiştir. Ele alınan DİBS 90 exante reel ve expost reel faiz oranlarına ilişkin ulaşılan sonuçları genel olarak değerlendirmek gerekirse: (i) Türkiye ekonomisi için hem exante hem de expost reel faiz oranları yüksek bir süreğenliğe sahiptir. (ii)Exante reel faiz oranlarının süreğenliğinin değişkenliği expost reel faiz oranlarının süreğenliğindeki değişkenlikten daha yüksektir. Öte yandan, (iii) teorik olarak beklentilerle karşılaştırıldığında ilk olarak, mali baskınlığın ortadan kalktığı 2005 yılı sonrasında, geçici olarak da olsa azalması öngörülen süreğenlik kayan pencere yönteminde exante reel faiz oranlarında görülebilmektedir. Süreğenlikteki azalışın, iv) expost reel faiz oranlarında ortaya çıkışı daha geç ve çok da beklenildiği ölçüde yüksek bir oranda değildir. İkinci olarak, v) 2011 yılı başı itibariyle her iki reel faiz oranının süreğenliği ciddi olarak azalmaktadır. Bu durum, tüketim temelli varlık fiyatlandırma modeli çerçevesinde ele alındığında, Türkiye ekonomisi için kredi büyümesinin büyük boyutlara ulaştığı ve tasarruf oranlarının gerçekten de rahatsız edecek derecede düşük seyrettiği bu dönem için oldukça tutarlı bir sonuçtur. 


\section{KAYNAKLAR}

Andrews, Donald,W.K. - Chen, Hong Y. (1994), “Approximately median-unbiased estimation of autoregressive models", Journal of Business and Economic Statistics, No. 12, pp. 187-204.

Belbute, Jose Manuel - Caleiro, Antonio. (2013), “Cross Country Evidence on Consumption Persistence", International Journal of Latest Trends in Finance and Economic Science, Vol.3, No2, pp. 440-455.

Caleiro Antonio. (2012), “Output Persistence in Portugal”, International Journal of Latest Trends in Finance and Economic Science, Vol.2, No3, pp. 206-210.

Sonali, Das - Rangan, Gupta - Patrick, T. Kanda- Monique, Reid - Christian, K. TipoyMulatu, F. Zerihun. (2012), "Real Interest Rate Persistence in South Africa: Evidence and Implications" Economic Change and Resturucting, December,2012.

Dias Daniel - Marques Carlos Robalo. (2010), "Using Mean Reversion As a Measure of Persistence", Economic Modelling, No. 27, pp. 262-273.

Diebold, Francis - Inoue, Atsushi. (2001), "Long Memory and Regime Switching”, Journal of Econometrics, No. 105, pp. 131-159.

Gil Alana, Luis. (2004), "Modelling the US real GNP with fractionally integrated techniques", Applied Economics, Vol. 36, No. 8, pp. 873-879.

Gil-Alana, Luis - Moreno, Antonio. (2012) "Fractional integration and structural breaks in U.S. macro dynamics", Empirical Economics, Vol. 43, Np. 1, pp. 427-446.

Kiefer, Nicholas M. - Vogelsang, Timothy. (2002), "Heteroskedasticity-Autocorrelation Robust Standard Errors Using The Bartlett Kernel Without Truncation", Econometrica, Vol. 70, No. 5, pp. 2093-2095.

Kutlar, Aziz - Turgut, Tuba. (2006), "Türkiye'deki Bașlıca Ekonomi Serilerinin ARFIMA Modelleri ile Tahmini ve Öngörülebilirliği”, Kocaeli Üniversitesi Sosyal Bilimler Enstitüsü Dergisi, Cilt 11, Say1 1, ss. 120-149.

Lai, Kon, S. (1997), "Long-term Persistence in the Real Interest Rate: Some Evidence of a Fractional Unit Root", International Journal of Finance and Economics, Vol. 2, No. 3, pp. 225-235.

Marques, Carlos Robalo. (2004), “Inflation Persistence: Facts or Artefacts” Europan Central Bank Working Paper Series, No 371, June.

Mishkin, Frederic S.. (2007), "Inflation Dynamics", International Finance, Vol. 10, No. 3, pp. 317-334.

Neely, Christopher J. - Rapach, David E. (2008), "Real Interest Rate Persistence: Evidence and Implications", Federal Reserve Bank of St. Louis Review, Vol. 90, No. 6, No. 609-41. 
Rose, Andrew K. (1988), “Is the Real Interest Rate Stable?”, The Journal of Finance, Vol. 43, No. 5, pp. 1095-1112.

Rotenberg, Julio - Woodford, Michael. (1997), “An Optimization Based Econometric Framework for he Evoluation of Monetary Policy” : NBER Macroeconomics Annual 1997, Vol. 12, pp. 297-361.

Svensson, Lars E. O. (1997), "Optimal Inflation Targets, Conservative Central Banks and Linear Inflation Contracts”, American Economic Review, Vol. 87, No. 98-114.

Tsay Wen Jen, (2000), "Long memory story of the real interest rate", Economics Letters, Elsevier, Vol. 67, No. 3, pp. 325-330.

Turgutlu, Evrim. (2004), "Fisher Hipotezinin Tutarlılığının Testi: Parçalı Durağanlık ve Parçalı Koentegrasyon Analizi”, DEÜ İ̈BF Dergisi, Cilt 19, Sayı. 2, ss. 55-74.

Yurttagüler, İpek M. - Kutlu, Sinem. (2013), "Reel Faiz Oranının Uzun Hafıza Modeli ile İncelenmesi: Türkiye Örneği”, Maliye Dergisi, Sayı 164, Ocak - Haziran, ss. 208-219. 